\section{Bangladesh Youth}

OR Summary 34

FINAL REPORT

PENDING

\section{Link Adolescent Reproductive Health Resources to Increase Access}

In Bangladesh, school and community education schemes increased young people's understanding of reproductive health, and the establishment of links between schools and adolescent-friendly clinics increased the use of reproductive health services. Several organizations are using project materials in programs for adolescents and other vulnerable groups.

\section{Background}

Adolescents, who make up about 25 percent of the population of Bangladesh, have limited access to reproductive health information and services. With the age at marriage increasing, young people are vulnerable to a variety of reproductive health risks, including unwanted pregnancy and sexually transmitted infections (STIs).

In 1999 FRONTIERS worked with the Ministry of Health, the Urban Family Health Partnership (UFHP), and two nongovernmental partners to test the feasibility, impact, and cost of several interventions to improve the reproductive health of adolescents aged 13 to 19 . The 18-month intervention took place in two experimental urban sites, while a third similar control site received prevailing services.

Both sites received the community intervention, which involved sensitization and outreach to community stakeholders (parents and religious and community leaders) to encourage local support. Out-of-school adolescents were offered a

20-session "life skills" curriculum that included reproductive health; and peer educators organized community events with reproductive health themes. The experimental sites also received a clinical component, in which providers were trained to offer a variety of affordable, adolescentfriendly services. One site also received a schoolbased intervention, in which trained teachers

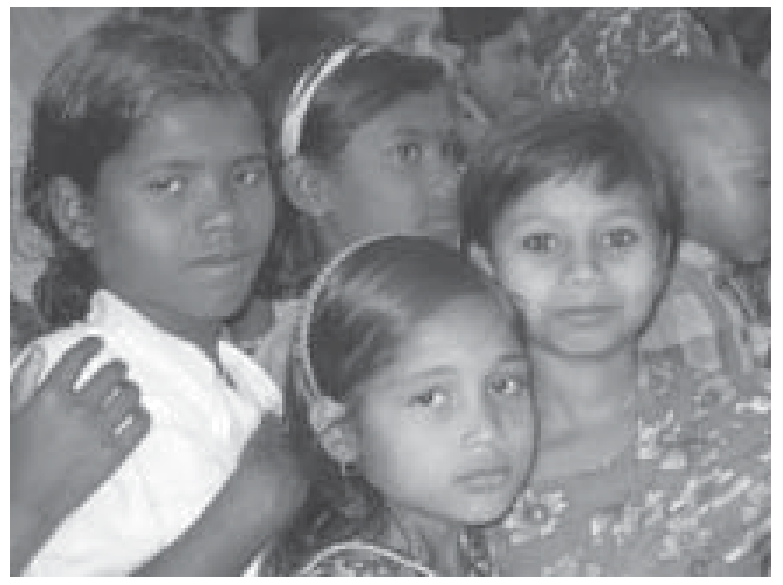

provided the life skills curriculum to eighth- and ninth-level students (aged 14 or 15).

\section{Findings}

- Almost all fathers (90\%) approved of school-based sex education and clinical services. About 75 percent of mothers expressed approval of such education, though less than half (42\%) of mothers and almost no fathers provide reproductive health information at home.

- Sexual activity outside of marriage is infrequent. Of 2,626 unmarried adolescents surveyed at baseline, only 5 percent ( 127 boys and 3 girls) were sexually experienced. Among this group, approximately one quarter used a family planning method during the most recent sexual encounter. Condom use at all three sites increased following the intervention; but the increase was higher at the intervention sites (12\% and 19\%) than at the control site (5\%). 
- The school-based intervention increased overall knowledge of several aspects of reproductive health, though knowledge levels varied. Nearly all adolescents, for example, had heard of HIV/AIDS; and knowledge of how the virus is transmitted increased from 66 percent to 84 percent. However, less than half of adolescents could name three other STIs; and knowledge of a woman's fertile period remained low.

- Nearly 5,000 adolescents received at least one service from youth-friendly clinics. The majority (87\%) obtained reproductive health services - mainly tetanus toxoid (TT) vaccines for girls who were pregnant or contemplating marriage. Clinic attendance was strongest in the site where all three interventions took place (see Figure).

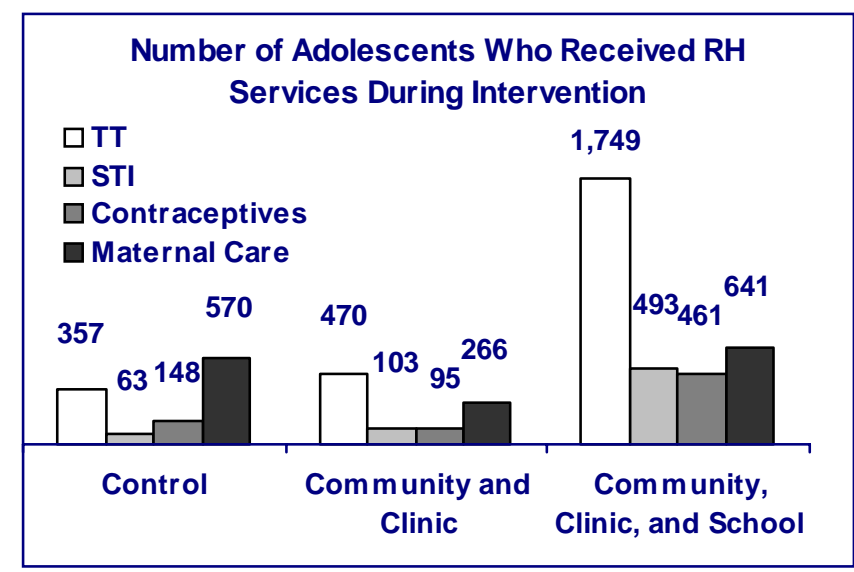

Source: Bhuiya 2003

- Community-based outreach had mixed results. Over 6,000 out-of-school adolescents attended the classes held by community facilitators, while another 2,000 obtained reproductive health information from peer educators. However, reaching out-of-school boys was challenging, as many were working and could not attend the educational sessions.
- The combined incremental cost of all three interventions was US $\$ 41,388$. The incremental cost of the clinic-based services was relatively low $(\$ 2,352)$ because it built upon the existing service delivery structure and training materials. The average financial and non-financial costs of the communityand school-based interventions were similar, about $\$ 12,000$ each.

\section{Utilization}

- The Ministry of Health and Family Welfare used the study findings in support of a proposal for schoolbased HIV/AIDS education to the Global Fund to fight AIDS, Tuberculosis and Malaria (GFATM). In addition, Save the Children (UK) included the teaching model and outreach material in their program; and several national organizations will use project materials to assist vulnerable women.

- In 2002, the school and clinic interventions were expanded to 34 additional schools and 88 health facilities.

\section{Policy Implications}

- Programs to improve reproductive health should include parental education, particularly for mothers, to facilitate discussion of sexual matters with their children.

- Reproductive health topics should be incorporated into national programs to train teachers. Training for clinicians should also include education on providing appropriate services for youth. Linking services with community resources is key to utilization.

September 2003

Bhuiya, Ismat, Ubaidur Rob, Asiful H. Chowdhury, Laila Rahman, Nazmul Haque, Susan Adamchak, Rick Homan, and ME Khan. 2004. "Improving adolescent reproductive health needs in Bangladesh," FRONTIERS Final Report. Washington DC: Population Council, Available at www.popcouncil.org/frontiers/pubs_types/finalreports.html or by email: frontiers@pcdc.org

This project was conducted with funds from the U.S. AGENCY FOR INTERNATIONAL DEVELOPMENT (USAID) under Cooperative Agreement Number HRN-A-00-98-00012-00. 